\title{
Rethinking the relationship between instructors and physics education researchers
}

\author{
Andrew Elby๑* \\ Department of Teaching \& Learning, Policy \& Leadership, \\ University of Maryland, College Park, Maryland 20742, USA \\ Sevda Yerdelen-Damar \\ Department of Mathematics and Science Education, Boğaziçi University, Istanbul 34342, Turkey
}

(Received 3 July 2019; accepted 7 February 2020; published 4 December 2020)

\begin{abstract}
[This paper is part of the Focused Collection on Curriculum Development: Theory into Design.] In the "standard" physics education research curriculum-development model, researchers are cast primarily as producers of curricula and instructors are cast primarily consumers, i.e., adopters and adapters. We illustrate a complementary model in which researchers" curricular modules, and also their "pure" research unattached to curriculum development, can serve as instructionally generative fodder that inspires and loosely guides instructors in creating their own curricular materials. Drawing on experiences from our graduate student days, we show how particular curricula and research papers influenced our curriculum development and instruction in particular ways. We then argue that the physics education ecosystem could benefit if researchers were more intentional about creating potential instructionally generative fodder, and we suggest ways to do so. Although not intended to replace the standard curriculum-development model, which has a history of producing effective tutorials and other curricular modules, our alternative model casts the researcher and instructor as co-equal contributors to the research-based yet creative process of curriculum generation.
\end{abstract}

DOI: 10.1103/PhysRevPhysEducRes.16.020151

\section{INTRODUCTION}

In the "standard model" of the PER-instructor ecosystem that dominates the published physics education research (PER) literature on curriculum development [1], the relationship between researchers and instructors is analogous to that of producers and consumers. PER teams do basic research on student thinking, use the results to inform the generation of curricula, and refine the curricula through cycles of testing and improvement [2]. Instructors then adopt the curricular materials, perhaps adapting them.

In this paper, we use our own experiences as instructors and curriculum developers to illustrate a complementary model of the research-instructor relationship, a model that blurs the distinction between producers and consumers. In this model, PER supplies not final-form curriculum, but rather, instructionally generative fodder-insights into learning, instructionally relevant theoretical lenses, proposed instructional goals, often but not always illustrated by examples of curricular materials. Instructors then

\footnotetext{
"elby@umd.edu, he/him
}

Published by the American Physical Society under the terms of the Creative Commons Attribution 4.0 International license. Further distribution of this work must maintain attribution to the author(s) and the published article's title, journal citation, and DOI. generate their own curricular materials and/or instructional strategies, drawing inspiration from that fodder.

We illustrate this model with examples from our own experiences. When Andy was pursuing his teacher certification and master's degree in science education, he read research by Hammer $[3,4]$ about epistemological beliefs in physics and their effects on students' approaches to learning. This research helped Andy organize and refine his instructional intuitions about, for instance, the difference between piecemeal learning and coherence seeking. Using these refined intuitions, Andy developed tutorials with an explicit agenda of fostering high school students' epistemologies [5].

Years later, as a doctoral student, Sevda read research about physics epistemologies by Elby [5], Hammer [4,6], and others. She also read the University of Maryland Open Source Tutorials in Physics Sensemaking [7,8], which include an explicit epistemological agenda similar to that of Andy's high school tutorials. For Sevda, those papers and tutorials, along with research she was reading about metacognition and active learning in science, inspired a vision of high school curricular modules structured by the "7E" model—Eisenkraft's [9] refinement of the "5E" model [10] — but including an epistemological and metacognitive agenda. These modules are not an adaptation of the Maryland tutorials; they are original creations reflecting Sevda's instructional intuitions as refined by multiple 
sources of instructionally generative fodder and adapted to the local school culture and broader Turkish educational system in which Sevda's modules would be embedded [11].

After illustrating ways in which we turned other scholars' research papers and curricular modules into instructionally generative fodder for our own early instruction and curriculum development efforts, we discuss how physics education researchers can be more intentional about creating such fodder for instructors-without disrupting their production of classroom-ready curriculum. In doing so, we address a critique of our argument: Can future PER scholars' experiences as novice instructors and developers count as an existence proof of the feasibility and productivity of our fodder-based model of the researcher-instructor relationship? But first, we review models of the relationship between researchers and instructors.

\section{MODELS OF RESEARCHER-INSTRUCTOR RELATIONSHIPS}

After presenting common models of researcher-instructor relationships, we will argue that the "new" model we are proposing is not new at all —and indeed, has been present for decades, though rarely if ever foregrounded in the PER literature. So, our contribution is making the "new" model explicit.

By instructors, we mean both college-level and $\mathrm{K}-12$ teachers.

\section{A. The standard model}

As mentioned above, in the published PER curriculum development literature [1], the standard model of the researcher-instructor relationship is one of producers and consumers. Physics education researchers do the research and development to create written curricula [2], and instructors adopt and perhaps adapt those materials [12]. We note that the prevalence of this model is reinforced not just by cultural norms in education but by entrenched structural features of both the $\mathrm{K}-12$ and higher education systems [13]. Researchers, especially when they win grants, have the time and resources to do research and development. K-12 teachers have extensive teaching (and other) responsibilities that make it difficult to develop their own curricular materials from scratch [14]. In addition, many teachers are constrained by school- or districtmandated curricula, textbooks, and/or testing regimens [15]. At the college level, finding collaborators or mentors to help create or implement collaborative active-learning opportunities for students can be difficult, and the penalties for productive failures that often precede eventual success - student complaints and bad course evaluations-can be stifling $[16,17]$. As an anonymous referee pointed out, multiple kinds of structures and communities are pushing back against these constraints [18], partly by blurring the boundaries between the community of research-based curriculum developers and the community of instructors, including the scholarship of teaching and learning [19], faculty learning communities $[20,21]$ facilitated by their own members or by a deliberately chosen education researcher [22]. Still, many faculty members continue to face the constraints mentioned above. So, while we see problems with the strict division of labor and associated power hierarchies embedded in the standard model, we do not intend this paper as a critique of those working within the model. Indeed, we acknowledge and celebrate the excellent, often canonical materials produced within this model [23-25].

In the standard model, curriculum is generally intended to be used as written; instructors are not encouraged to modify the curricular materials significantly. Instructor guides and instructor professional development focus on what the $\mathrm{K}-12$ literature calls "high-fidelity" implementation-using the materials as written and teaching in a way that mirrors the intent of the developers [26]. For PER-based physics tutorials and other curricular modules, this generally involves using the worksheets and implementing teaching strategies to support small-group active learning [27].

\section{B. The loosened standard model: Open source}

In the loosened standard model, researchers or experienced instructors produce curricular materials intended to be "working drafts" that instructors can then modify, perhaps extensively, to fit into their courses [28]. So, the curricular materials are disseminated as modifiable, opensource documents. The instructor's guides present the rationale behind various instructional choices - the ordering of certain questions, the inclusion of an unusual question format, etc. - not so much to justify those choices but to invite instructors to evaluate if those rationales apply to their particular course and students $[7,8,28]$. Ideally, the instructor's guides provide guidance for adaptations-what question or section could be deleted, what additional kinds of prompts an instructor could decide to add on the fly during instruction, and so on. And ideally, faculty learning communities would form to create and share modifications and associated guidance.

Systemic factors make this model difficult to enact, for both researchers and instructors. Generating, testing, and refining instructor guides that support instructors in making adaptations is time-consuming. (Indeed, Andy was unable to finish that work in his first project aimed at producing open-source tutorials.) Textbook publishers are not interested in open-source materials, though dissemination tools like PhysPort [29] alleviate this problem. Instructors, as mentioned above, face constraints and (dis)incentives that make it hard to find the time and collaborators needed to reflect and make thoughtful adaptations to curricular modules they might be encountering for the first time. Still, a few PER projects have used this model $[7,8,28,30]$, and other emerging projects have started taking advantage 
of technological developments to push projects in this direction. For instance, the Living Physics Portal project [31], currently in development and beta testing, will include infrastructure to share modifications of open-source Introductory Physics for Life Sciences (IPLS) course materials and to support community efforts to modify such materials.

Although this model invites more of an intellectual partnership between researchers and instructors than the standard model does, an asymmetry remains; the instructor is supported more in adapting the researcher-generated curriculum than in using the curriculum as inspiration to generate their own materials, and the researcher always writes the first draft.

\section{C. "Educative curriculum"}

From the fields of curriculum studies and mathematics education research at the $\mathrm{K}-12$ level comes the notion of educative curriculum materials, curriculum aimed at students but also intended to promote teacher learning $[32,33]$. Science education researchers have also taken up this notion (e.g., Ref. [34]). This model is not orthogonal to those presented above.

We are not aware of PER curriculum development efforts that explicitly foreground the educative features of the curriculum for helping instructors learn content and pedagogical content knowledge. Yet, PER is aware of the educative capacity of curriculum. For instance, at the University of Washington and elsewhere, one goal of having TAs work through the tutorials during TA preparation meetings is to help them better understand the physics they will teach [2]. Anecdotally, instructors who read or use Chabay and Sherwood's Matter and Interactions materials on electric circuits and other topics [35] often comment that it helps them understand "introductory" physics in a new way. Andy's first exposure to PER curriculum, at a multi-day short course run by Laws, Sokoloff, and Thornton, helped him think of kinematics in new ways. Layered onto the loosened standard model, an educative curriculum stance toward curriculum development invites sustained attention to how instructors interact with the curriculum - what they get out of it besides the materials themselves. Yet, this stance maintains a hierarchy between researchers and instructors, in that researchers are framed as having knowledge that instructors would benefit from learning, but not vice versa.

\section{Researcher-instructor partnerships}

In this model, a group of researchers and instructors, perhaps including people who wear both hats, work as coequal partners in all phases of curriculum development. A recent surge of scholarly interest in research-practice partnerships between universities and K-12 schools highlights the opportunities and challenges of keeping the work flowing efficiently while also ensuring that all stakeholders' voices are heard and valued [36].

In PER, some research groups working with $\mathrm{K}-12$ teachers take up a key element of this model by centering the needs and expertise of the teachers and working collaboratively. For instance, The Maine Center for Research in STEM Education, in some of its projects, works collaboratively with $\mathrm{K}-12$ teachers to modify the curriculum the teachers are using and to conduct classroom-based research [37]. At the undergraduate level, the Science Education Initiatives at the Universities of Colorado and British Columbia [22,38], in which postdoctoral fellows with STEM education research expertise work on teams with instructors to improve courses, can be viewed as a researcher-instructor partnership. Some faculty engage in a co-teaching model in which one or both faculty members has PER experience $[39,40]$. Although this model can play out as an expert helping a novice, it can also play out as a more equal sharing of ideas and expertise.

\section{E. Our proposed model: Creating and using instructionally generative fodder}

This model borrows elements of the loosened standard model and educative curriculum, but with a broadened vision of what researcher-produced materials might be "educative" for instructors and a broadened vision of how instructors can take up those materials. Instead of serving as (perhaps adaptable) materials for students, the researcher's curricular materials are used as inspiration for instructors. The instructor can adapt bits of the materials themselves, of course. But the instructor is also invited to treat the curriculum as fodder from which to glean instructionally relevant theoretical lenses, proposed instructional goals, insights into learning, and task or question models and templates, all in the service of generating their own curricular materials and instructional approaches. In other words, the researcher's curriculum serves as instructionally generative fodder for the instructor. Ideally, the researcher's curriculum would be supplemented by other materialsposition papers, research studies, etc.- that also provide ideas and inspiration to the instructor. Indeed, those research studies and position papers can serve as instructionally generative fodder even when not coupled to curricular materials. We give detailed examples below.

Before continuing, though, we need to make two clarifications. First, we are not arguing that physics education researchers should take a break from their "regular" research and curriculum development to create materials specifically for instructors. Redish's Teaching Physics book [41], for instance, was created to supply instructors with what we are calling instructionally generative fodder. But to write the book, Redish needed a sabbatical from his regular work. While we hope other researchers will take sabbaticals to create high-quality 
instructionally generative fodder, our argument here is that physics education researchers can and should write up their "regular" research papers and instructional modules in ways that maximize their potential as instructionally generative fodder.

Second, we note that aspects of model E pervade the PER community. We suspect that almost all tutorial and conceptual lab writers since the early 1990s have explicitly or implicitly used the University of Washington (UW) Tutorials [23] and/or the RealTime Physics labs [24] to get ideas about questions types (like "student debate" questions), about creating coherent conceptual flows, and so on. We certainly have. Furthermore, the power of these exemplary curricula to serve as instructionally generative fodder for other instructors and curriculum writers is enhanced by the associated research studies. The early papers about UW tutorials (e.g., Refs. [42-44]) introduce readers to the instructional goal of targeting a specific student difficulty (or closely connected set of difficulties) without getting bogged down in mathematical details. The pre-post questions introduced in those papers, and the Force and Motion Concept Exam [45] style questions introduced in early papers about RealTime Physics and Interactive Physics Demonstrations, help readers understand the learning goals. Our point is that the instructionally generative fodder is not just the curricular materials themselves; it is the curricular materials plus associated research studies plus associated assessment instruments. This fodder introduces and illustrates theoretical lenses (e.g., conceptual reasoning and conceptual difficulties), instructional goals (e.g., targeting conceptual difficulties), and insights into learning (e.g., the power of small-group active learning), some or all of which can feed into a new curriculum development effort.

In brief, we contend that exemplary curricula like UW Tutorials and RealTime Physics play two different roles in PER, corresponding to different models of researcherinstructor relationships. First, and by design, the materials serve as exemplary classroom-ready curricular modules within the standard model. Second, and more emergently, these curricular materials-coupled with their associated research products-have served as instructionally generative fodder to later instructors and curriculum writers. We have not studied what percentage of PER curriculumdevelopment projects draw on previous projects in this way. The point of this paper is that some instructors, including the two of us as graduate students, have used previous PER work as instructionally generative fodder to inspire and guide their own curriculum development. So, by intentionally writing up their classroom-ready curricular materials and associated research papers in ways that maximize their potential as instructionally generative fodder, researchers can potentially invite a wider population of instructors to participate in this model of the researcherinstructor relationship.

\section{OUR STORIES OF FINDING INSPIRATION IN INSTRUCTIONALLY GENERATIVE FODDER}

In this theoretical paper, the "data" consist of our stories of digesting instructionally generative fodder and creating or teaching curriculum. The stories serve as

(i) existence proofs that both curricular materials and research, coupled or uncoupled, can serve as instructionally generative fodder;

(ii) case studies illustrating the idiosyncratic trajectories instructors can follow as their teacher identities and the ways in which they choose and take up instructionally generative fodder develop in strong interaction with each other.

Although these stories are largely descriptive, they reflect a situative perspective - Greeno's version of situated learning theory-regarding teacher learning [46-48]. In this perspective, learning is highly situated in particular activities and contexts, in our case creating instructional materials and using them in the classroom, but is not necessarily embedded in a community of practice. As in other versions of situated learning theory (e.g., Refs. [49,50]), a metaphor of "learning as becoming" guides a researcher's attention to the interconnectedness of changes in learners' understandings or practices and changes in their identity, who they are as a person, as manifested in their interactions with others-with students while teaching, with teachers while collaborating, and with other researchers and curriculum developers when doing research and development.

For the purposes of this paper, illustrating a model of the researcher-instructor relationship, these stories are appropriate "data." Methodologically, in presenting the stories, we draw on one aspect of autoethnography, the idea that a person's experiences can shed light on a broader cultural phenomenon (e.g., researcher-instructor relationship in the PER community). Our stories, however, resemble purely retrospective autoethnographies [51-53], not relying on careful journaling and other tools used by many autoethnographers [54].

Furthermore, instead of organizing our stories by theme, we present largely chronological narratives, for two reasons. First, the chronological flow more accurately reflects our haphazard, highly contingent experiences. Second, the fact that our curriculum writing depends on these contingent experiences is a point of our paper, standing in contrast to a cleaner story of a curriculum writer adopting and applying a single coherent theoretical framework. We think the mechanism by which learning theories and epistemological commitments influence curriculum creation is not the cold cognitive application of that framework to the instructional goals and constraints. Rather, it is the result of a prior long-term process during which the curriculum writer's instructional intuitions, tutorial-writing habits of mind, theoretical frameworks, and personal experiences as a learner and teacher all affect each other as they develop over time, leaving them highly 
interconnected. We want our narratives to illuminate, not obscure, this messiness.

\section{A. Andy's story}

In this section, I (Andy), writing in the first person but with editing help from Sevda, describe how PER curricula and also pure research served as instructionally generative fodder for my epistemologically oriented high school teaching and curriculum development in the late 1990s. The resulting instructional materials are mostly tutorials (activity worksheets) and accompanying homework assignments aimed at helping high school physics students gain a deep conceptual understanding of the physics by building on their everyday reasoning, and associated epistemological stance that learning physics is the refinement of everyday thinking.

Admittedly, the 1990s was kind of a blur; my recollections about my own thinking are not $100 \%$ accurate. To write this, I did review the worksheets and lesson plans I used as a high school teacher, and I found my folder of old academic papers from that period (hard copies). Minor inaccuracies in the details below, however, do not invalidate the point that both curricular materials and "pure" research served as instructionally generative fodder for me, and that an idiosyncratic personal journey as opposed to a coherent plan of study or professional development regimen led me to take up particular pieces of research and curriculum as instructionally generative fodder in particular ways.

My first exposure to PER came in the early 1990s as a physics (but not PER) graduate student. Because I was involved in some (non-PER-based) course reforms at my university, I attended a Chautauqua Short Course led by Priscilla Laws, David Sokoloff, and Ron Thornton. They introduced small group "active learning" techniques and curricula, specifically RealTime Physics and Workshop Physics modules [55] and associated assessments and technological tools. I learned what really good conceptual questions and conceptual lab sequences can look like, which later helped me to create my own. So those instructional materials-accompanied by readings, assessments, and ideas from the short course-later served as instructionally generative fodder.

Later, after finishing my doctorate, I stuck around Berkeley for a few extra years because my partner was attending law school there. While working toward my teacher certification and Master's degree in science education (1995-1997), I worked with Andy diSessa and learned about the knowledge-in-pieces framework for modeling students' intuitive knowledge [56]. Also, diSessa handed me David Hammer's dissertation about physics students' epistemological beliefs, thinking I would find it interesting. I did. Partly because I was soon to be teaching in local high schools, I started thinking about how I could help students develop more sophisticated epistemologies. I also started collaborating with
Barbara White and John Frederiksen's research group, also at Berkeley, to create an epistemology survey, which later became the Epistemological Beliefs Assessment for Physical Science (EBAPS) [57,58]. (I did not know that the University of Maryland PER group was creating something similar [59].) Below, I give an example of high school curriculum partly inspired by Hammer's work and by my work on EBAPS. But first, I think it is illuminating to explore why I resonated so strongly with that work, strongly enough for it to serve as my primary instructionally generative fodder. After all, not everything I read in grad school etched traces into my early curricular materials. In short, I now realize, Hammer's work resonated because I have been attentive to my own approach and other students' approaches to learning physics since high school, long before I had words or theoretical frameworks for thinking and talking about the beliefs corresponding to these approaches.

Evidence for this long-standing interest comes from a bit of epistemological humor shared by my high school AP physics teacher and me. He was roped into teaching the class-physics was not his primary expertise, as he was the first to acknowledge. When he presented a solution to a physics problem that was clearly just plugging and chugging, I would write down "P. I. T. B." in my notes and flash it at him. It stands for Plug in the Barf, an elision of "plug in the formula" and "regurgitate the problem-solving procedure." We had co-invented the term, and he sometimes used it himself. Yes, I was a sarcastic pain in the butt in high school, but here is the point: in class and also while tutoring other students, I was acutely aware of more memorization-based vs conceptually based ways of approaching learning and problem solving. A big part of my budding physics identity was tied up in being the kind of student who tries to understand. In college I felt bad about myself during days or weeks when I needed to "give up" and just P. I. T. B. So, when I read the student quotes Hammer used to illustrate the distinction between seeking coherence and treating physics as loosely connected pieces, and between treating physics knowledge as consisting primarily of concepts (expressible as formulas) vs consisting primarily of formulas, it all felt natural to me. I felt like I knew those students from my study groups and tutoring experiences. More formally, Hammer's $[3,4]$ work gave me a theoretical lens for seeing more clearly into phenomena I had already been inclined to notice and care about. I think this is why Hammer's work became instructionally generative fodder for me, as illustrated by my high school instructional materials [5].

Let me give one example not contained in my earlier paper [5]. After students had worked through the Newton's 2nd law lab described in Sec. IV A 1 of Ref. [5], I assigned the following homework. (I had reason to think that most of these students did the assigned readings.) 
In lab last week, most people seemed surprised to find an apparent contradiction between common sense and Newton's $2^{\text {nd }}$ law $\left(F_{\mathrm{net}}=m a\right)$, for a car cruising at constant velocity. But the night before the lab, you read a textbook chapter about Newton's laws. Why didn't you notice the apparent contradiction while doing the reading?

I'm not "yelling" at you or blaming you; I know you're careful, conscientious readers. That's why it's interesting to think about why the apparent contradiction went unnoticed. What could you and/or the textbook have done differently to help you discover-and possibly resolve-the apparent contradiction?

Although I do not remember if I had this in mind when generating this question, Hammer's [4] interviews include segments where the student reads a section of their physics textbook and thinks aloud while making sense of it.

The instructional generativity of Hammer's work also manifested itself in lessons what were less "meta." One example of this also brings in another thread of research I found instructionally generative, Bruce Sherin's symbolic forms [60]. (I learned about this work before its publication when I sat in on the diSessa research group.) Sherin, then a post-doc, argued that "marriages" between algebraic structures such as " $\square=\square+\square+\cdots$ " and conceptual schema such as the whole is constituted by its parts form a vocabulary of meaning-infused algebraic expressions and equations that physics students use to interpret and construct equations. From the rich examples of student reasoning in Sherin's work, I knew that students were capable of "guessing" equations and discussing the rationale behind their guesses. And, inspired by Hammer's work [3], I was intent on helping students conceive of their emerging physics knowledge as the "refinement of everyday thinking" (Einstein [61]). So, with my AP Physics level high school class in 1998 as the first lesson on the universal law of gravitation, I drew Fig. 1 on the board, explained what it meant, and asked students to work in small groups to guess the force with which the two asteroids attract each other.

Most groups came up with either $M_{1} M_{2} / r$ or $\left(M_{1}+M_{2}\right) / r$. After the part of the lesson described here, the class discussed the need for a proportionality constant, and its meaning. But first, the class discussed the reasoning behind these "guesses." Students ended up agreeing that both

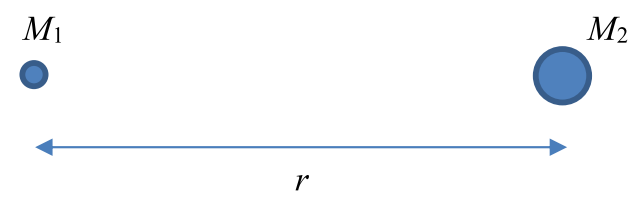

FIG. 1. Two asteroids, of mass $M_{1}$ and $M_{2}$, separated by distance $r$. Andy asked students to "guess" the equation for the attractive gravitational force acting between the asteroids. expressions capture the idea that more mass leads to greater gravitational attraction, and less distance between the asteroids leads to greater attraction-as expected, given diSessa's closer is stronger $p$ prim [56]. I asked students to come up with a nonexperimental strategy for figuring out which of these two reasonable guesses is more plausible. One small group came up with the idea of considering a tiny $M_{2}$. Elevating this idea, I asked all the student groups to consider the case where the second asteroid is tiny (i.e., a speck of dust). Most groups then converged on $M_{1} M_{2} / r$ as better capturing their intuition. After tagging this as yet another example of "limiting cases" reasoning, I told them the correct equation and promised that the $r^{2}$ denominator would make more intuitive sense later in the course. The main point of the lesson, which I explicitly restated, is the continuity between their everyday reasoning and physics concepts and equations.

In summary, my story illustrates the haphazard way in which I encountered and took up instructionally generative fodder during my time as a physics graduate student and teaching assistant, then as an education student, then as a high school teacher, and then as a physics education researcher. Consistent with a situative view of teacher learning [46-48], my uptake of this fodder both affected and was affected by my developing identity as a physics instructor who prioritizes helping students see learning physics as the refinement of everyday thinking.

\section{B. Sevda's story}

For my doctoral study, I wanted to develop a physics unit that could be tested against the way physics is usually taught in elite Turkish high schools. As described below, my readings in science and physics education led me to create a conceptually focused unit with a " $5 \mathrm{E}$ " structure [10] familiar to Turkish science teachers but with epistemological and metacognitive learning goals embedded in ways inspired by research papers and curricular modules I encountered.

Before developing a bunch of instructional materials during my doctoral study, I read a great deal of research studies related to educational psychology, science education, and PER. I became aware of important constructs related to students' learning. The most significant ones (to me) included conceptual and epistemological understandings of students, scientific inquiry as an active teaching strategy, and metacognitive development of students. I aimed to develop a curriculum in which these constructs were blended in a systematic way.

I was first introduced to PER while taking the "Historical Development of Basic Concepts of Science" course offered by Dr. Ali Eryilmaz in 2005. In this course, we discussed several pioneering articles on PER. I became aware of conceptual surveys such as the FCI [62] and MBT [63], and of PER groups. Inspired by readings from this and subsequent courses, and since I thought Turkish high schools underemphasized conceptual, qualitative 


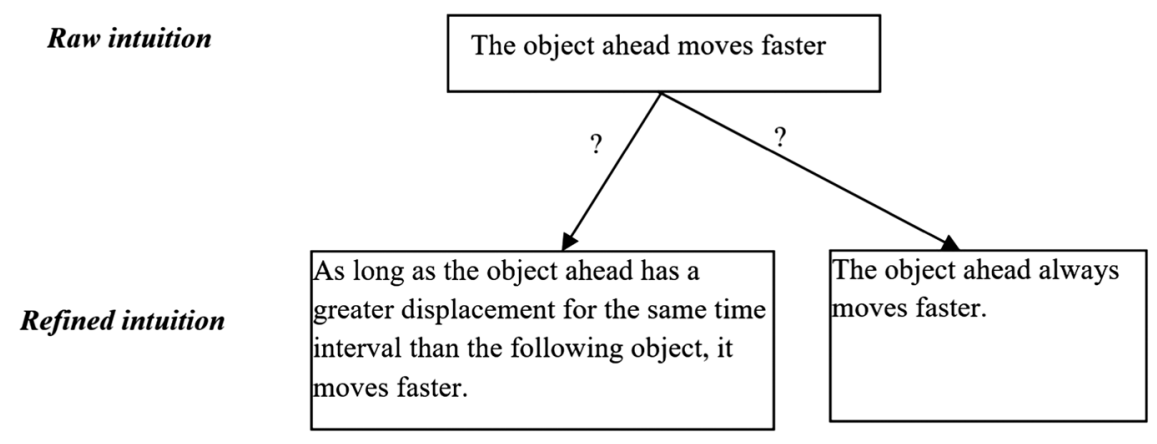

Which of those two refinements agrees with relative motion principle?

FIG. 2. The refinement diagram for "the object ahead moves faster" intuitive knowledge.

reasoning, I decided to develop a curriculum for Turkish high school students to address their conceptual understandings. For the conceptual questions employed in my curriculum, I examined well-known curricular materials in PER such as the UW Tutorials [23] and Eric Mazur's peer instruction book [64]. In addition, I searched PER group websites to find whether they provide any conceptual questions used in their research studies. At that time, two PER groups provided access to their materials, at Universities of Maryland and Colorado. I also benefited from canonical PER articles (e.g., Refs. [65,66]).

In general, I knew about the effectiveness of inquirybased teaching strategies from my readings on science education and PER. After reading the study of Eisenkraft [9], I decided to use the 7E learning cycle (elicit, engage, explore, explain, elaborate, evaluate, and extend) as a framework of my curriculum.

While I continued my doctoral education, I read the study titled "Helping physics students learn how to learn" [5]. Encountering this study was the milestone of my doctoral study since this article led me to other related studies which helped me develop the epistemological part of my curriculum and my main research interest.

The study of Redish and Hammer [67] led me to find and make sense of the University of Maryland "Tutorials in Physics Sense-making" [7]. The Maryland tutorials served as a guide when I developed epistemological activities integrated into the 7E learning cycle model. I developed activity sheets like the Maryland tutorials. The activity sheets were the main instructional materials on which students worked in groups of four or five. The activity sheet consisted of 7 main parts corresponding to seven phases of the 7E learning cycle model. In creating them, I used the Maryland tutorials in two ways. One was to adapt parts of those tutorials with minor changes and to blend them with other activities in my curriculum. Another use was to develop epistemological activities similar to those in the Maryland tutorials. For example, one common strategy in the Maryland tutorials is the "refinement lesson" developed by Elby [5] to guide students to understand that learning physics involves refining one's own intuitive ideas in order to reconcile them with formal physics knowledge. Using this idea, I developed a similar refinement lesson addressing a common intuition: being ahead implies going faster [68]; see Fig. 2.

During the same refinement lesson, the following question asked students to think about the contradictions between common sense and scientific knowledge.

A. (Work individually) Most people think being ahead implies having gone faster. Some of you used this intuition and contradicted with relative motion formula. Which one of the following best expresses your attitude toward this contradiction?

(1) We shouldn't dwell on these kinds of contradictions and should instead focus on learning exactly when relative motion does and doesn't apply.

(2) There's probably some way to reconcile common sense with relative motion, though I don't see how.

(3) Although physics usually can be reconciled with common sense, here the contradiction between physics and common sense is so blatant that we have to accept it.

Briefly explain why you chose the answer you chose.

B. Discuss your answer with your group. Is there a consensus or do people disagree?

This question was adapted from a question in the Maryland tutorial on Newton's third law [7]. In that tutorial, the original question asks students to think about the contradiction between an intuition-in a collision between a lighter and heavier object, the lighter object reacts more during a collision - and Newton's third law. Moreover, as a professor, I continue to develop and use "refinement lessons" for my pre-service physics teachers.

The homework assignments in my curriculum also indicate how research helped me generate instructional materials. The idea underlying those assignments came from the study of Hammer and Elby [6]. I really enjoyed and got excited when I read that article, in which they 


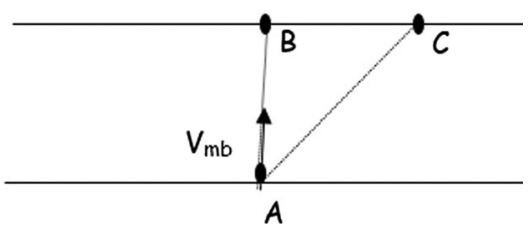

FIG. 3. Diagram accompanying the three-part homework question below.

discussed an approach to activating students' everyday intuitive physics knowledge and helping students to reconcile their intuitive knowledge with formal physics knowledge. I used their idea to structure my conceptual questions employed in group work sessions and homework assignments. One example from a homework is given as follows [68]:

(1) On his first fishing day, a young fisherman traveled with a motorboat across a river from point A to point $\mathrm{B}$ on a windless day. On the second fishing day, he again directed his motorboat towards point $\mathrm{B}$ but because of the wind he reached point $\mathrm{C}$ instead (Fig. 3). On both days, the motor engine ran at a constant rate and headed straight across the river. Compare the times taken in both journeys? Explain your reasoning.

(2) How might other people who don't know physics answer this question and why might they respond like that?

(3) Is there a way to reconcile the common-sense idea underlying other people's ideas with your own reasoning in this case?

Interestingly, like Andy, I was also inspired by the same student quotes from Hammer [4] and created the following reading assignment.

After you answer the question 1, please read from 69 page to 71 page in your textbook as you answer questions 2 and 3.

(1) Consider you push teacup at a steady pace on a table. The frictional force exerted by the table on the cup opposes its motion. Intuitively, is the force exerted by your hand greater than, less than, or equal to that frictional force? Explain your reasoning?

(2) While you are reading the text or after you read it, ask yourself questions that check whether you understand what you are reading. Write down a few of those questions.

(3) Are there any instances where your intuitive knowledge used in your everyday life has contradicted what you have read? If there are, please specify those instances.

While reading articles related to scientific inquiry and personal epistemology, I met another important concept: "metacognition." It was repeatedly mentioned across those articles. Both inquiry and personal epistemology researchers pointed out the necessity of metacognition for effective learning (e.g., Refs. $[69,70]$ ).

In order to guide students into metacognitive thinking, I wrote my own metacognitive prompts after I read various research studies on metacognition. I integrated these prompts into the different parts of my curriculum to guide students to be aware of and reflect on their own conceptual and epistemological understandings, and to help students monitor and evaluate their own thinking processes. Here are some examples.

The first phase of the 7E learning cycle is the elicit phase, the main aim of which is to elicit students' prior understandings [9]. In this stage, I tried to activate students' everyday intuitive knowledge with conceptual questions blended with metacognitive prompts such as "Do you agree with your friends," "Does your friend's explanation intuitively make sense to you?" The collection of prompts was provided in teacher guides developed for each activity sheet, similar to the instructor's guides in the Maryland tutorials to help teachers implement and adapt the activity sheet as intended.

For the explore phase of the 7E cycle, I sometimes adapted experiments from the RealTime Physics Mechanics module [71] and from research tasks on force and motion. But before and after conducting these experiments, additional questions prompted metacognitive thinking processes related to students' conceptual and epistemological understandings. For instance, at the beginning of the activity sheet on Newton's 2nd law, students worked on following questions, very similar to those in the RealTime Physics module.

\section{A. (Work individually).}

1. One box pulled by a string moves at a steady pace across a floor. Intuitively, is the force exerted on the box by the string less than, greater than, or equal to the force exerted by the floor. Please explain the reasoning behind your ideas.

2. The same box is pulled by a steady force on a frictionless floor.

a) Does velocity of the box increase, decrease or stay constant?

b) Does acceleration of the box increase, decrease or stay constant?

3. If the magnitude of a steady force exerted on the box pulled on a frictionless floor gets doubled, how the acceleration of the box change?

B. (Work together). Please discuss questions above with your friends. When you share your ideas related to the question, please explain and support the reasoning behind your ideas. Do not change your previous responses given individually.

After this part, students tested their ideas using microcomputer-based laboratory tools. Then, students were 
asked to reconcile their predictions (prior understandings or common sense) with experimental results by figuring out what led them to wrong predictions. The activities eventually led students to Newton's second law, after which they were asked to reflect on their learning process - an addition to the RealTime Physics questions.

(Work together) The formula you have just reached might have been given directly to you. But you reached that formula after passing through some stages. What might the purpose of these stages be?

Other phases of the 7E cycle also included metacognitive prompts asking students to monitor and evaluate their own understandings. For example, "Can you give examples of situations where your ideas work well?" "Do you have any idea why your ideas do not work in this situation?" "What are the differences between those situations and this situation?" In the last phase of the 7Es, students answered the same questions they answered in the first phase of the $7 \mathrm{E}$ learning cycle. After students revised their responses to the questions, they were prompted with "Is there anything that you have refined in your prior understandings? If so, how do you reconcile your prior and current ideas?"

In summary, my instructional unit drew on a variety of curricular modules in a variety of ways: particular conceptual and epistemological questions, templates and exemplars of conceptual and epistemological question types, instructional goals spanning conceptual, epistemological, and metacognitive development, a coarse-grained organization for inquiry science units (the 7Es), and more general inspiration for what inquiry-based introductory physics teaching and learning might look like. The research I read served as its own instructionally generative fodder and also enhanced my understanding of the curricular modules I was drawing upon, thereby enhancing their generativity and developing my identity as a synthesizer of different threads of physics and science education research - which in turn helped sustain my synthesizing efforts.

\section{DISCUSSION}

\section{A. Summary of the main take aways}

We will start our discussion by summarizing the main points emerging from Andy's and Sevda's stories.

\section{Instructional generativity of curriculum is increased by related research}

The ability of pieces of curricula to serve as instructionally generative fodder is increased by research-not just efficacy research showing that the curriculum "works," but other research illustrating the theoretical lenses and constructs associated with the curriculum. For instance, for Andy, hearing Laws, Sokoloff, and Thornton explain the theory behind their curricular materials helped make the
RealTime Physics labs [24] more generative for his own attempts to write conceptual questions. Similarly, for Sevda, reading research on student epistemologies by Hammer, Elby, and others $[5,6,72]$ helped turn the Maryland tutorials into instructionally generative fodder for formulating her epistemologically focused questions.

\section{Curriculum can serve as instructionally generative fodder in multiple ways}

We both used other researchers' curriculum in multiple ways. The most straightforward uses fit into the Loosened Standard Model (open source): Andy adapted particular activities and conceptual flows from RealTime Physics [24], and Sevda adapted particular questions from the Maryland open-source tutorials [7]. But both of us also used previous curricula as templates for creating new questions and activities. For instance, Andy created his own conceptual lab activities using the Predict $\rightarrow$ Do it $\rightarrow$ Discuss and Resolve sequencing of many RealTime Physics sequences. Sevda, as illustrated above, created her own "refinement lessons," complete with raw vs refined intuition diagrams. Zooming out even further, most of Andy's early curriculum is based on the RealTime Physics prototype of a conceptual lab and the University of Washington prototype of a tutorial. The idea of using lab activities to develop conceptual understanding without worrying about quantitative analysis-it seems obvious to Andy now, 25 years later, but it was mind blowing at the time. Similarly, Sevda borrowed the general idea of a 7E lesson from Eisenkraft [9], and the general idea of an explicit epistemological question from the Maryland tutorials. For her, embedding epistemology and metacognition questions into physics classwork and homework is now natural and obvious.

\section{A range of noncurricular materials can serve as instructionally generative fodder}

It is no surprise that a piece of curriculum can be generative for other curriculum developers. Andy's and Sevda's stories show the diversity of other sources of instructional generativity. Sevda explicitly adopted an inquiry framework (Eisenkraft's 7E), and Andy sometimes used a predict $\rightarrow$ observe $\rightarrow$ explain learning cycle from what he learned at the Laws-Sokoloff-Thornton short course [73]. Sevda and Andy both adapted into homework questions a particular research task from Hammer [4], asking students to reflect on whether and how a textbook passage makes sense. Andy was inspired to have students guess the equation for gravitational attraction by Sherin's research tasks in his paper about symbolic forms [60]. Sevda became aware of the power of metacognition for enhancing inquiry and epistemologically oriented curriculum by reading theory papers (e.g., Refs. [6,69]). In brief, the constructs and theoretical lenses encountered in "pure" research papers-epistemological views, symbolic forms, 
metacognition-were particularly instructionally generative for Andy and Sevda.

\section{The notion of instructionally generative fodder recasts the researcher-instructor relationship in some ways but not others}

To situate this point, we first review how our model of the researcher-instructor relationship centered around instructionally generative fodder compares to the other models summarized in Sec. II. Like the standard model and loosened standard model, our model usually has as its first step a researcher creating and disseminating a curricular module, though the first step could also be a research product. However, unlike in the standard model, which does not scaffold curricular adaptions, and unlike in the loosened standard model, which invites and scaffolds modifications to the researcher-produced curricular module, our model involves instructors using the researcherproduced curricular module as inspiration to create their own curriculum, drawing on the original curricular module in a variety of ways illustrated in Sevda's and Andy's stories. In this way, the researcher-produced curricular module serves as educative curriculum in the sense that it helps the instructor construct new understandings of physics and how it might be taught.

Does our model based on instructionally generative fodder mitigate the hierarchical power and status relationship between researcher and instructor, as envisioned by research-practice partnerships? Mostly no, with a little bit of yes. In our model, the researcher is the provider of the instructionally generative fodder, consisting partly of educative curriculum; there's no automatic pathway in the model for instructors to share their knowledge and insights with the researchers. The hierarchical asymmetry remains. Slightly countering the hierarchy, however, is the fully shared agency over curriculum: the instructor is not a consumer or adapter of the research-produced curriculum, but is the creator of a new curriculum. The instructor's own ideas and their digested version of the researcher's ideas (in the instructionally generative fodder) both feed into the new curriculum. Still, there's not a real partnership between the researcher and instructor, a weakness of our model that we address below.

Of course, instead of always creating our own curriculum, Sevda and Andy sometimes used polished PER-based curriculum with just minor or no modifications. Which leads to our next point.

\section{B. Disclaimers: what we are not arguing}

Now we discuss a potential unintended interpretation of our argument. A reader might ask, "Are you saying that instructors should create all their own materials, and PER curriculum developers should stop crafting polished curricular modules?"
That is not what we are saying. First, even an obstinate instructor who insists on creating all their own materialsand Andy was kind of like this before wising up-can find polished PER-based curricula to be instructionally generative. Second, and more important, few instructors have time to create all their own curricular materials from scratch, even if their institution gives them the freedom to do so. Just modifying existing materials can become overwhelming. Polished curricular modules like tutorials therefore have a place in the physics education ecosystem, as evidenced by their continued use, at least among a subset of faculty [74].

Nonetheless, as previous work shows, instructors create their own curricular materials or significantly adapt existing materials, at least some of the time, to try to fit the instruction goals, constraints, and needs of their particular courses and students [75-78]. Our argument is that instructionally generative fodder can help instructors do so. It is therefore productive for physics education researchers to produce instructionally generative fodder, including but not limited to curricular modules, as a complement to producing classroom-ready curricula. As mentioned above, advocates of research-practice partnerships, among others, have argued for the multiple benefits of including K-12 teachers in all phases of the design of classroom-ready curricula [79-81]. We are making a separate argument, that researchers can indirectly help instructors with whom they are not directly working, by providing instructionally generative fodder.

\section{Why can it be beneficial for instructors to create their own curricula?}

So far in this paper, we have assumed without argument that it is productive for instructors to create their own curricula building on ideas they glean from instructionally generative fodder. To support this claim, we draw on our experiences and on the science education research literature.

We both experienced a kind of joy and agency when reading curricula or research that resonated with us and then using our creativity to generate and teach-or in Sevda's case, watch other teachers teach-novel curricula. For Sevda, this joy and agency helped keep her going during the difficult process of formally testing a curriculum and writing up the results in a dissertation. For Andy, the repeated moments of joy helped keep him from burning out during a difficult first two years of high school teaching. These benefits make generating our own curriculum worthwhile even if the final product is no better than an off-the-shelf curriculum.

Research suggests that our experiences mirror broader trends: $\mathrm{K}-12$ teachers who feel more autonomy and agency, over curriculum and other aspects of their professional jobs, experience greater job satisfaction and lower burn out [82-85]. 
We acknowledge that in some cases, a new, untested, instructor-generated curricular module might not "work" as well as off-the-shelf curriculum would have, despite the instructor's knowledge of the particular goals, constraints, and needs of their course and students. But it is equally true that a polished PER-based module, implemented by an instructor who did not design it in a classroom context different from where the module was tested and refined, might not work as well as something the instructor designs-inspired in part by the polished module - to fit their particular needs.

\section{Will this model really work for all K-16 instructors?}

We now address the most glaring potential flaw in our argument. We have used the stories of two future physics education researchers, Andy and Sevda as graduate students, to illustrate the idea of instructionally generative fodder and to make plausible the claim that supplying instructors with such fodder is a productive use of researchers' time. But can "regular" time-starved instructors, those not engaged in the beginning stages of a PER career, find the time and inspiration to (re)frame curriculum and/or research they encounter as instructionally generative fodder that helps them create their own curricular materials?

We do indeed see lack of time, along with institutional constraints, as significant barriers to instructors creating their own materials. K-12 and college-level instructors face different constraints and (dis)incentives, but those barriers are significant barriers in both cases [14-17]. Still, as noted above, instructors sometimes adapt materials or create their own, sometimes inspired by something they read or heard [75-78]. If provided time and remuneration-during summers, for instance- to take part in workshops that support instructors in creating their own materials, they could do so more regularly.

An experience of Sevda's supports this claim. Teaching a course to three high school physics teachers pursuing a Master's degree in physics education, Sevda introduced the teachers to "refinement lessons." After a three-hour class, Sevda asked them to create their own refinement lessons they would then use with their own high school students. One week later, the teachers came back with well-developed refinement lessons.

We hypothesize that research-practice partnerships, or more narrow researcher-instructor partnerships such as faculty learning communities with an education researcher involved, are promising structures in which to embed the use of instructionally generative fodder. As part of extended partnerships between the researchers and instructors, the participants can get to know each other. They can then choose readings, for the whole group or for particular individuals, that are likely to resonate and become instructionally generative fodder. As emphasized above, such readings could consist of both curricular modules and research. When a participant becomes inspired to create their own curricular module, the other participants could help by providing ideas, feedback, encouragement, and so on.

The issue remains, however, of whether most instructors have the inclination and ability to (re)frame curriculum and/ or research they encounter as instructionally generative fodder and to create their own curricular modules accordingly, even occasionally. We have not researched this question. As an anonymous reviewer pointed out, many instructors might be creating curricular modules in this way, but since they are unpublished, the PER community is unaware of them. On the other hand, we acknowledge that case studies of outstanding K-12 teachers who enthusiastically take up professional development in creative ways are not representative.

To motivate research about whether and how instructors take up instructionally generative fodder, we would like to offer an analogical counternarrative to the "average instructors can't do that" narrative. Back in the dawn of PER in the 1970s and 1980s, many physicists held the view that "average" students are incapable of the kinds of deep conceptual reasoning and learning that students can do. But then, PER started developing curricular materials and discussion-based classroom environments in which average students did engage in deep conceptual reasoning and learning, as evidenced by gains on standardized conceptual assessments. Given the right kinds of materials and support, average students could indeed learn physics in ways thought to be accessible only to "talented" students. We hypothesize that the same dynamic applies to instructors: With the right kinds of extended professional development and support, perhaps most instructors could cook up and digest instructional generative fodder from curricula and research they encounter. At least, this hypothesis deserves exploration, just as it was worthwhile to explore whether average students could take part in deep conceptual thinking and learning.

\section{E. Increasing the instructional generativity of PER curriculum and research}

How can PER produce even better instructionally generative fodder? To clarify this question, we first note that we are not referring to researchers' books and articles aimed specifically at instructors, such as classic works by Redish [41] and Arons [86]. These resources often include previously produced research and curricular exemplars, partially digested by the authors. In this section, however, we are asking how researchers can make more generative, as instructional fodder, the "regular" research and curricular products they produce.

The question is complicated because a curricular or research artifact is instructionally generative to the extent it inspires an instructor in instructionally actionable ways, and this depends not just on the artifact but on what resonates with a particular instructor at a particular time. 
For instance, as described above, Andy's personal history and identity as a learner and instructor led him to resonate with Hammer's epistemology research. Similarly, metacognition research connected to epistemology resonated strongly with Sevda.

Still, (over)generalizing from our experiences, we can at least speculate about what characteristics make a PER artifact more likely to be instructionally generative to an appreciable number of $\mathrm{K}-16$ instructors.

\section{Curricular modules-what might increase their instructional generativity?}

First, transparency may be important. A curricular module is more "transparent" when the documents associated with it help instructors understand the designer's rationale for particular choices of questions, sequences, and so on [1]. For instance, when learning about RealTime Physics [24] materials from their creators, Andy learned about the fine-grained rationale behind some of the activity sequences, and about things that were tried and did not work. By helping him enter the "problem space" of the RealTime Physics creators, these sometimes-informal conversations made those materials more instructionally generative for Andy. Similarly, the rationales behind instructional choices in the Maryland tutorials $[7,8]$ contained in the instructor's guides, accompanied by research papers highlighting the theoretical lens of "epistemological resources" and how instructors can leverage them (e.g., Ref. [6]), helped make the Maryland tutorials more instructionally generative for Sevda.

A valuable part of transparency, we suspect, would be providing instructors with a deeper peek into the messy black box of curriculum development - productive failures that led to revisions, subtle rewordings that seemed to make a big difference, and so on.

A second accompaniment to a curricular module that could increase its generativity is video of students working on the module. See, for instance, the instructor materials accompanying the Maryland tutorials [7,8], as well as Scherr's periscope video lessons [87,88]. An instructor watching these videos through their own interpretive lenses, which may differ from the lenses of the curriculum designers, might come up with a different way to scaffold students' learning of the targeted topic.

\section{Research papers-what might increase their instructional generativity?}

Looking back over our stories, we notice that neither of us mentioned the "instructional implications" section of any research paper. What stuck with us were examples of student thinking. We do not advocate skimping on instructional implications; we are just noting that the substance of the research findings themselves, especially when they included analyzed examples of student reasoning, have the capacity to resonate strongly with instructors.

Of course, good reasons exist to include numerous rich examples of student reasoning in research papers [89], independent of considerations of instructional generativity. And barriers exist to doing so, including page limits, the need to prioritize quantitative results in experimental and quasiexperimental studies, and some reviewers' preferences. So, our point is just that the prospect of increased instructional generativity provides yet another reason for researchers - and reviewers, and journal editors - to push back against these barriers.

Another facet of some research papers that we found to be instructionally generative was explicit attention to tapping into physics educators' intuition when introducing and explaining their theoretical constructs. For instance, Sherin [60] starts his paper with an example explicitly intended to resonate with physics educators, in order to help readers enter a mindset for understanding his focal construct, symbolic forms. We speculate that research papers are most likely to serve as instructionally generative fodder when the authors frame their work not just as establishing a claim but as helping readers see phenomena in new ways.

\section{CONCLUSION}

We illustrated a model of the researcher-instructor relationship meant to complement the standard model in which researchers are primarily producers of curricula and instructors are primarily consumers (adopters and adapters). In this alternative model, researchers' curricular modules - and also their pure and applied research — can serve as instructionally generative fodder that inspires and guides instructors in creating their own curricular materials. We used our own stories to illustrate what this can look like. Finally, we argued that it would be productive for the physics education ecosystem if physics education researchers, in addition to doing research and development to produce classroom-ready curricular modules, also focused on (i) making their research and curricula more likely to serve as instructionally generative fodder for instructors, and (ii) offering professional development aimed at helping instructors find PER work that resonates with them, and supporting instructors in creating their own materials inspired by that fodder. 
[1] H. Sabo and A. Elby, this issue, Rethinking the division of labor between tutorial writers and instructors with respect to fostering equitable team dynamics, Phys. Rev. Phys. Educ. Res. 16, 020142 (2020).

[2] L. C. McDermott, Oersted medal lecture 2001: "Physics Education Research - the key to student learning", Am. J. Phys. 69, 1127 (2001)

[3] D. M. Hammer, Students' beliefs about conceptual knowledge in introductory physics, Int. J. Sci. Educ. 16, 385 (1994).

[4] D. M. Hammer, Epistemological beliefs in introductory physics, Cognit. Instr. 12, 151 (1994).

[5] A. Elby, Helping physics students learn how to learn, Am. J. Phys. Phys. Educ. Res. Suppl. 69, S54 (2001).

[6] D. M. Hammer and A. Elby, Tapping epistemological resources for learning physics, J. Learn. Sci. 12, 53 (2003).

[7] A. Elby, R. E. Scherr, T. L. McCaskey, R. Hodges, E. F. Redish, D. M. Hammer, and T. Bing, Open Source Tutorials in Physics Sense-making: Suite I, https://www .physport.org/curricula/MD_OST/.

[8] R. E. Scherr, A. Elby, T. L. McCaskey, R. Hodges, E. F. Redish, D. M. Hammer, and T. Bing, Open Source Tutorials in Physics Sensemaking: Suite II, https://www .physport.org/curricula/MD_OST/.

[9] A. Eisenkraft, A proposed 7E model emphasizes "transfer of learning" and the importance of eliciting prior understanding, Sci. Teach. 70, 56 (2003).

[10] R. W. Bybee, J. A. Taylor, A. Gardner, P. Van Scotter, J. C. Powell, A. Westbrook, and N. Landes, The BSCS $5 E$ Instructional Model: Origins and Effectiveness (BCBS, Colorado Springs, Co, 2006).

[11] S. Y. Damar, The effect of the instruction based on the epistemologically and metacognitively improved 7e learning cycle on tenth grade students' achievement and epistemological understandings in physics, $\mathrm{Ph} . \mathrm{D}$. thesis, Middle East Technical University, Ankara, 2013 (to be published).

[12] N. D. Finkelstein and S. J. Pollock, Replicating and understanding successful innovations: Implementing tutorials in introductory physics, Phys. Rev. ST Phys. Educ. Res. 1, 010101 (2005).

[13] C. E. Coburn, S. Bae, and E. O. Turner, Authority, status, and the dynamics of insider-outsider partnerships at the district level, Peabody J. Educ. 83, 364 (2008).

[14] S. A. Melnick and D. G. Meister, A comparison of beginning and experienced teachers' concerns, Educ. Res. Quart. 31, 39 (2008).

[15] K. J. Anderson, Science education and test-based accountability: Reviewing their relationship and exploring implications for future policy, Sci. Educ. 96, 104 (2012).

[16] M. Dancy and C. Henderson, Pedagogical practices and instructional change of physics faculty, Am. J. Phys. 78, 1056 (2010).

[17] C. Henderson, M. Dancy, and M. Niewiadomska-Bugaj, Use of research-based instructional strategies in introductory physics: Where do faculty leave the innovationdecision process?, Phys. Rev. ST Phys. Educ. Res. 8, 020104 (2012).

[18] M. Borrego and C. Henderson, Increasing the use of evidence-based teaching in STEM higher education: A comparison of eight change strategies, J. Eng. Educ. 103, 220 (2014).

[19] P. Hutchings, M. T. Huber, and A. Ciccone, The Scholarship of Teaching and Learning Reconsidered: Institutional Integration and Impact (John Wiley \& Sons, New York, 2011), Vol. 21.

[20] K. L. Sirum, D. Madigan, and D. J. Klionsky, Enabling a culture of change: A life science faculty learning community promotes scientific teaching, J. Coll. Sci. Teach. 38, 28 (2009).

[21] A. Furco and B. E. Moely, Using learning communities to build faculty support for pedagogical innovation: A multicampus study, J. Higher Educ. 83, 128 (2012).

[22] S. V. Chasteen, K. K. Perkins, W. J. Code, and C. E. Wieman, The science education initiative: an experiment in scaling up educational improvements in a research university, in Transforming Institutions: Undergraduate STEM Education for the 21st Century, p. 125 (2016), https://sei.ubc.ca/handle/seima/2171.

[23] L. C. McDermott and P. S. Shaffer, Tutorials in Introductory Physics (Prentice Hall, Upper Saddle River, NJ, 1998).

[24] D. R. Sokoloff, R. K. Thornton, and P. W. Laws, RealTime Physics: Active Learning Laboratories (Wiley, New York, 1999).

[25] R. Beichner, The SCALE-UP Project: A Student-Centered Active Learning Environment for Undergraduate Programs, An invited white paper (National Academy of Sciences, Washington, DC, 2008).

[26] C. L. O'Donnell, Defining, conceptualizing, and measuring fidelity of implementation and its relationship to outcomes in $\mathrm{K}-12$ curriculum intervention research, Rev. Educ. Res. 78, 33 (2008).

[27] V. Otero, S. Pollock, and N. Finkelstein, A physics department's role in preparing physics teachers: The Colorado Learning Assistant Model, Am. J. Phys. 78, 1218 (2010).

[28] R. E. Scherr and A. Elby, Enabling informed adaptation of reformed instructional materials, AIP Conf. Proc. 883, 46 (2007).

[29] S. McKagan, A. Madsen, E. Sayre, and L. Strubbe, PhysPort: Supporting physics teaching with researchbased resources (American Association of Physics Teachers, College Park, MD, 2011), https://www.physport.org.

[30] S. Pollock, G. Passante, and H. Sadaghiani, Research as a base to develop adaptable curricula bridging instructional paradigms in quantum mechanics (National Science Foundation, Washington, DC, 2016).

[31] S. McKagan et al., Living Physics Portal (American Association of Physics Teachers, College Park, MD, 2019), https://www.livingphysicsportal.org.

[32] D. L. Ball and D. K. Cohen, Reform by the book: What isor might be- the role of curriculum materials in teacher learning and instructional reform?, Educ. Res. 25, 6 (1996).

[33] J. S. Bruner, The Process of Education (Harvard University Press, Cambridge, MA, 1977) (first published 1960).

[34] E. A. Davis and J. S. Krajcik, Designing educative curriculum materials to promote teacher learning, Educ. Res. 34, 3 (2005).

[35] R. W. Chabay and B. A. Sherwood, Electric and Magnetic Interactions (Wiley, New York, 1995). 
[36] C. E. Coburn and W. R. Penuel, Research-practice partnerships in education: Outcomes, dynamics, and open questions, Educ. Res. 45, 48 (2016).

[37] S. R. McKay et al., Investing in teachers' leadership capacity: A model from STEM education, Maine Policy Rev. 27, 54 (2018).

[38] S. Chasteen and W. Code, The Science Education Initiative Handbook (University of British Columbia Press, Vancouver, 2018).

[39] C. Henderson, A. Beach, and M. Famiano, Promoting instructional change via co-teaching, Am. J. Phys. 77, 274 (2009).

[40] L. E. Strubbe, J. Stang, T. Holland, S. B. Sherman, and W. J. Code, Faculty adoption of active learning strategies via paired teaching: Conclusions from two science departments, J. Coll. Sci. Teach. 049, 31 (2019).

[41] E. F. Redish, Teaching Physics with the Physics Suite (Wiley, New York, NY, 2003).

[42] L. C. McDermott and P. S. Shaffer, Research as a guide for curriculum development: An example from introductory electricity. Part I: Investigation of student understanding., Am. J. Phys. 60, 994 (1992).

[43] L. C. McDermott, P. S. Shaffer, and M. D. Somers, Research as a guide for teaching introductory mechanics: An illustration in the context of the Atwood's machine, Am. J. Phys. 62, 46 (1994).

[44] P. S. Shaffer and L. C. McDermott, Research as a guide for curriculum development-An example from introductory electricity. Part II: Design of instructional strategies, Am. J. Phys. 60, 1003 (1992).

[45] R. K. Thornton and D. R. Sokoloff, Assessing student learning of Newton's laws: The force and motion conceptual evaluation and the evaluation of active learning laboratory and lecture curricula, Am. J. Phys. 66, 338 (1998).

[46] J. G. Greeno, On claims that answer the wrong questions, Educ. Res. 26, 5 (1997).

[47] J. G. Greeno, A situative perspective on cognition and learning in interaction, in Theories of Learning and Studies of Instructional Practice (Springer, New York, 2011), p. 41.

[48] R. K. Saivyer and J. G. Greeno, Situativity and learning, in The Cambridge Handbook of Situated Cognition (Cambridge University Press, Cambridge, England, 2009), p. 304.

[49] J. Lave and E. Wenger, Situated Learning: Legitimate Peripheral Participation (Cambridge University Press, New York, 1991).

[50] E. Wenger, Communities of Practice: Learning, Meaning, and Identity (Cambridge University Press, Cambridge, England, 1998).

[51] A.C. H. Nowakowski, You poor thing: A retrospective autoethnography of visible chronic illness as a symbolic vanishing act, Qual. Rep. 21, 1615 (2016).

[52] T. A. Halvorsen, My face is more than me. A Nordic researcher in the South: An autoethnographic retrospective perspective, Int. Rev. Educ. 64, 845 (2018).

[53] G. A. Tilley-Lubbs, Good intentions pave the way to hierarchy: A retrospective autoethnographic approach, Michigan J. Commun. Serv. Learn. 16, 59 (2009).
[54] S. H. Jones, T. E. Adams, and C. Ellis, Handbook of Autoethnography (Routledge, London, 2016).

[55] P. Laws, Workshop Physics: Learning introductory physics by doing it, Change: Mag. Higher Learn. 23, 20 (1991).

[56] A. A. diSessa, Towards an epistemology of physics, Cognit. Instr. 10, 105 (1993).

[57] A. Elby, J. Frederiksen, C. Schwarz, and B. White, EBAPS: Epistemological Beliefs Assessment for Physical Science (American Educational Research Association, Washington, DC, 1997), p. 24.

[58] Epistemological Beliefs Assessment for Physical Science, http://www2.physics.umd.edu/ elby/EBAPS/home.htm.

[59] E. F. Redish, J. M. Saul, and R. N. Steinberg, Student expectations in introductory physics, Am. J. Phys. 66, 212 (1998).

[60] B. L. Sherin, How students understand physics equations, Cognit. Instr. 19, 479 (2001).

[61] A. Einstein, Physics and reality, J. Franklin Inst. 221, 349 (1936).

[62] D. Hestenes, M. Wells, and G. Swackhamer, Force Concept Inventory, Phys. Teach. 30, 141 (1992).

[63] D. Hestenes and M. Wells, A mechanics baseline test, Phys. Teach. 30, 159 (1992).

[64] E. Mazur, Peer Instruction (Prentice Hall, Upper Saddle River, NJ, 1997).

[65] J. Bowden, G. Dallalba, E. Martin, D. Laurillard, F. Marton, G. Masters, P. Ramsden, A. Stephanou, and E. Walsh, Displacement, velocity, and frames of referencephenomenographic studies of students understanding and some implications for teaching and assessment, Am. J. Phys. 60, 262 (1992).

[66] J. M. Monaghan and J. Clement, Use of a computer simulation to develop mental simulations for understanding relative motion concepts, Int. J. Sci. Educ. 21, 921 (1999).

[67] E. F. Redish and D. M. Hammer, Reinventing college physics for biologists: Explicating an epistemological curriculum, Am. J. Phys. 77, 629 (2009).

[68] S. Yerdelen-Damar and A. Eryllmaz, Promoting conceptual understanding with explicit epistemic intervention in metacognitive instruction: Interaction between the treatment and epistemic cognition, Res. Sci. Educ. 49, 1 (2019).

[69] L. D. Bendixen and D. C. Rule, An integrative approach to personal epistemology: A guiding model, Educ. Psychol. 39, 69 (2004).

[70] B. Y. White and J. R. Frederiksen, Inquiry, modeling, and metacognition: Making science accessible to all students, Cognit. Instr. 16, 3 (1998).

[71] D. R. Sokoloff, R. K. Thornton, and P. W. Laws, RealTime Physics, Module 1, Mechanics (Wiley-VCH, New York, 1998), pp. 288. ISBN 0-471-28379-7.

[72] B. K. Hofer and P. R. Pintrich, Personal Epistemology: The Psychology of Beliefs about Knowledge and Knowing (Lawrence Erlbaum, Mahwah, N.J., 2002).

[73] P. Laws, D. Sokoloff, and R. Thornton, Promoting active learning using the results of physics education research, UniServe Science News 13, 14 (1999).

[74] M. H. Dancy, A. V. Apkarian, M. Stains, E. Johnson, and J. Raker, Survey of physics, mathematics and chemistry 
faculty, in Physics Education Research Conference (PERC) (Provo, UT, 2019).

[75] C. Henderson and M.H. Dancy, Physics faculty and educational researchers: Divergent expectations as barriers to the diffusion of innovations, Am. J. Phys. 76, 79 (2008).

[76] C. V. Schwarz, K. L. Gunckel, E. L. Smith, B. A. Covitt, M. Bae, M. Enfield, and B. K. Tsurusaki, Helping elementary preservice teachers learn to use curriculum materials for effective science teaching, Sci. Educ. 92, 345 (2008).

[77] G. H. Roehrig, R. A. Kruse, and A. Kern, Teacher and school characteristics and their influence on curriculum implementation, J. Res. Sci. Teach. 44, 883 (2007).

[78] C. Henderson and M. H. Dancy, Impact of physics education research on the teaching of introductory quantitative physics in the United States, Phys. Rev. ST Phys. Educ. Res. 5, 020107 (2009).

[79] B. J. Reiser, J. P. Spillane, F. Steinmuler, D. Sorsa, K. Carney, and E. Kyza, Investigating the mutual adaptation process in teachers' design of technology-infused curricula, in Proceedings of the Fourth International Conference of the Learning Sciences, edited by B. Fishman and S. O'Connor-Divelbiss (Erlbaum, Mahwah, NJ, 2000), pp. 342.

[80] G. W. Shrader and L. M. Gomez, Design research for the living curriculum, in Computer Support for Collaborative Learning (CSCL), edited by C. Hoadley and J. Roschelle (Erlbaum, Stanford Univeristy, Palo Alto CA, 1999).

[81] G. Shrader, K. Williams, J. Lachance-Whitcomb, L.-E. Finn, and L. Gomez, Participatory design of science curricula: The case for research for practice, in Proceedings of the Annual Meeting of the American Educational Research Association, Seattle, WA (American Educational Research Association, Washington, DC, 2001).

[82] E. M. Skaalvik and S. Skaalvik, Teacher self-efficacy and perceived autonomy: Relations with teacher engagement, job satisfaction, and emotional exhaustion, Psychological reports 114, 68 (2014).

[83] L. C. Pearson and W. Moomaw, The relationship between teacher autonomy and stress, work satisfaction, empowerment, and professionalism, Educ. Res. Quart. 29, 38 (2005).

[84] M. S. Crocco and A.T. Costigan, The narrowing of curriculum and pedagogy in the age of accountability urban educators speak out, Urban Educ. 42, 512 (2007).

[85] A. M. Woods and J. Weasmer, Maintaining job satisfaction: Engaging professionals as active participants, The Clearing House 77, 118 (2004).

[86] A. B. Arons, Teaching Introductory Physics (Wiley, New York, 1997).

[87] R. E. Scherr and R. M. Goertzen, Periscope: Looking into learning in best-practices physics classrooms, Phys. Teach. 56, 100 (2018).

[88] Periscope Video Lessons (American Association of Physics Teachers), https://www.physport.org/periscope/?L=\% 2FLessons\%2Ecfm.

[89] D. Hammer and L. K. Berland, Confusing claims for data: A critique of common practices for presenting qualitative research on learning, J. Learn. Sci. 23, 37 (2014). 